\title{
Impact of Contaminated Fluid on the Working Performances of Hydraulic Directional Control Valves
}

\author{
Velibor Karanović1,* - Mitar Jocanović1 - Sebastian Baloš ${ }^{1}$ - Darko Knežević2 - Ivan Mačužić 3 \\ 1University of Novi Sad, Faculty of Technical Sciences, Serbia \\ 2University of Banja Luka, Faculty of Mechanical Engineering, Bosnia and Herzegovina \\ 3 University of Kragujevac, Faculty of Engineering, Serbia
}

The study aims to investigate the impact of solid particles on the directional hydraulic valve operation. Experiments have been performed for a certain number of operating cycles to measure the impact of the working fluid cleanliness level on the intensity of the wear on contact surfaces as well as on other failures in the operation of the directional control valve. For experimental purposes, a mechanically actuated control valve $4 / 2$ is used. The wear intensity of working elements was determined for different levels of oil contamination by solid particles. Also, experimental results have shown that there are differences between theoretically calculated and the measured flow through the radial clearance. By measuring pressure drop values during the fluid flow through the valve, it was found that oils with the lowest cleanliness level have a greater dispersion of the measured values. The results will contribute to better understanding the impact of working fluid cleanliness on possible defects and failures happening inside hydraulic system components.

Keywords: hydraulic systems, condition monitoring, tribology, wear

Highlights

- Hydraulic fluid contamination influence on directional valve performances has been experimentally investigated.

- $\quad$ System pressure, flow, and temperature are controlled within tolerated limits, and the solid particle contamination level is varied.

- Experimental measurements involve pressure drop across the valve, radial clearance between the piston and housing, and contaminated fluid flow through the clearance.

- $\quad$ Oil with higher contamination level increases the wear intensity, decreases measurement precision of pressure drop values, and slightly decreases leakage across clearances.

\section{INTRODUCTION}

It is very difficult to predict and precisely determine the impact of fluid cleanliness on the system operation or its components, due to many factors and a variety of hydraulic system applications. The hydraulic fluid contamination is an issue that can shorten the working life of hydraulic components, which has a direct impact on maintenance costs [1] to [3]. Also, contamination can be considered as a hydraulic system "intruder", which has a direct or indirect influence on system behaviour and parameters such as precision, response time, repeatability, controllability, etc. [4] and [5].

Many well-regarded companies and other institutions dealing with manufacturing, maintenance and testing of hydraulic systems and equipment, based on their own experience from practice and experimental research, claim that the working fluid contamination represents the main cause of failures in $70 \%$ to $80 \%$ cases [2] and [6] to [9]. Additionally, the requirements for more precise control and higher efficiency of hydraulic systems, have resulted in the decreased clearances between working elements of hydraulic components and the increased working pressure values [10]. Due to the decreased clearance size, the adverse impact of micron-size solid contaminants becomes evident. Although it is wellknown that solid contaminants are destructive to hydraulic system components, as well as to the working fluid itself, there was no internationally accepted method for objectively determination of contamination tolerance for systems or each component separately [11], until 2017. In 2013, was initiated and consequently published ISO 12669:2017 standard, developed for determining the required cleanliness level (RCL) for a system [12]. This standard is now under review for five years period.

Due to the lack of a standard procedure, the RCL choice is based on the system designer experience or on the third person recommendation (such as components manufacturer) and his experience. This doesn't mean that optimal cleanliness level was selected for the specific system operation.

The RCL selection by this method is strongly subjective, for which reason it does not provide consistency. Consequently, many system designers, as well as the users of hydraulic systems, are unsure and confused about the appropriate cleanliness level 
selection for a specific hydraulic system. Often, stricter requirements are applied regarding the working fluid cleanliness level, which produces a positive impact on the working life of the equipment but also a negative impact in terms of the increased maintenance costs (Fig. 1).

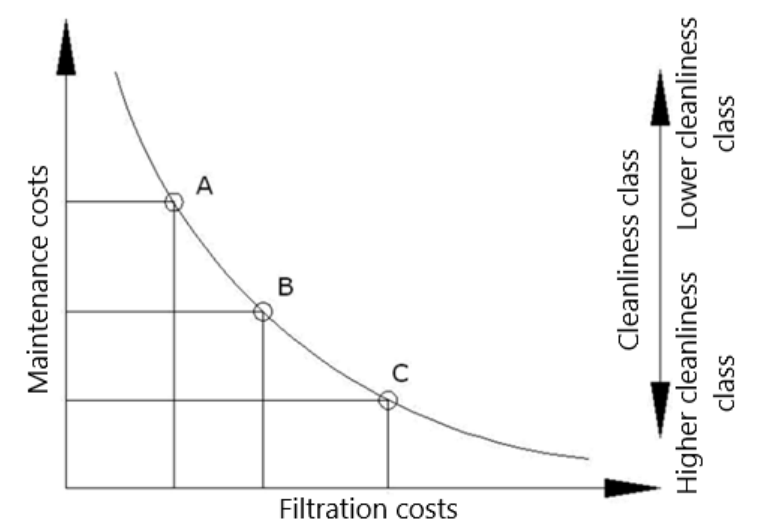

Fig. 1. Maintenance costs in relation to filtration costs depending on mineral oil cleanliness level (maintenance costs/filtration costs), in relation to the required oil cleanliness:

A - low cleanliness of oil/low filtration costs/high maintenance costs; $B$ - optimal cleanliness of oil/optimal filtration and maintenance costs; $\mathrm{C}$ - high cleanliness of oil/high filtration costs/ low maintenance costs
This study presents the research results regarding the impact of solid particles in oil on the wear intensity of contact surfaces of working elements in a hydraulic directional control valve, as well as on the leakage through clearances dependent on cleanliness levels of hydraulic oil.

\section{EXPERIMENTAL}

\subsection{Experimental Installation}

For the experiment, an installation according to the schematic shown in Fig. 2 was used.

As an object of experimental measurement, a mechanically actuated directional control valve $4 / 2$ is used within the installation. It has $l=4 \mathrm{~mm}$ axial working stroke, flow rate $Q=20 \mathrm{l} / \mathrm{min}$ and maximum working pressure $p=320$ bar.

\subsection{Measuring Instrumentation Used for Annular Gap Monitoring and Starting Values}

Measurement of the contact rings' diameters on the piston and in the valve body/housing was performed with a Carl Zeiss Contura G2 coordinate measuring

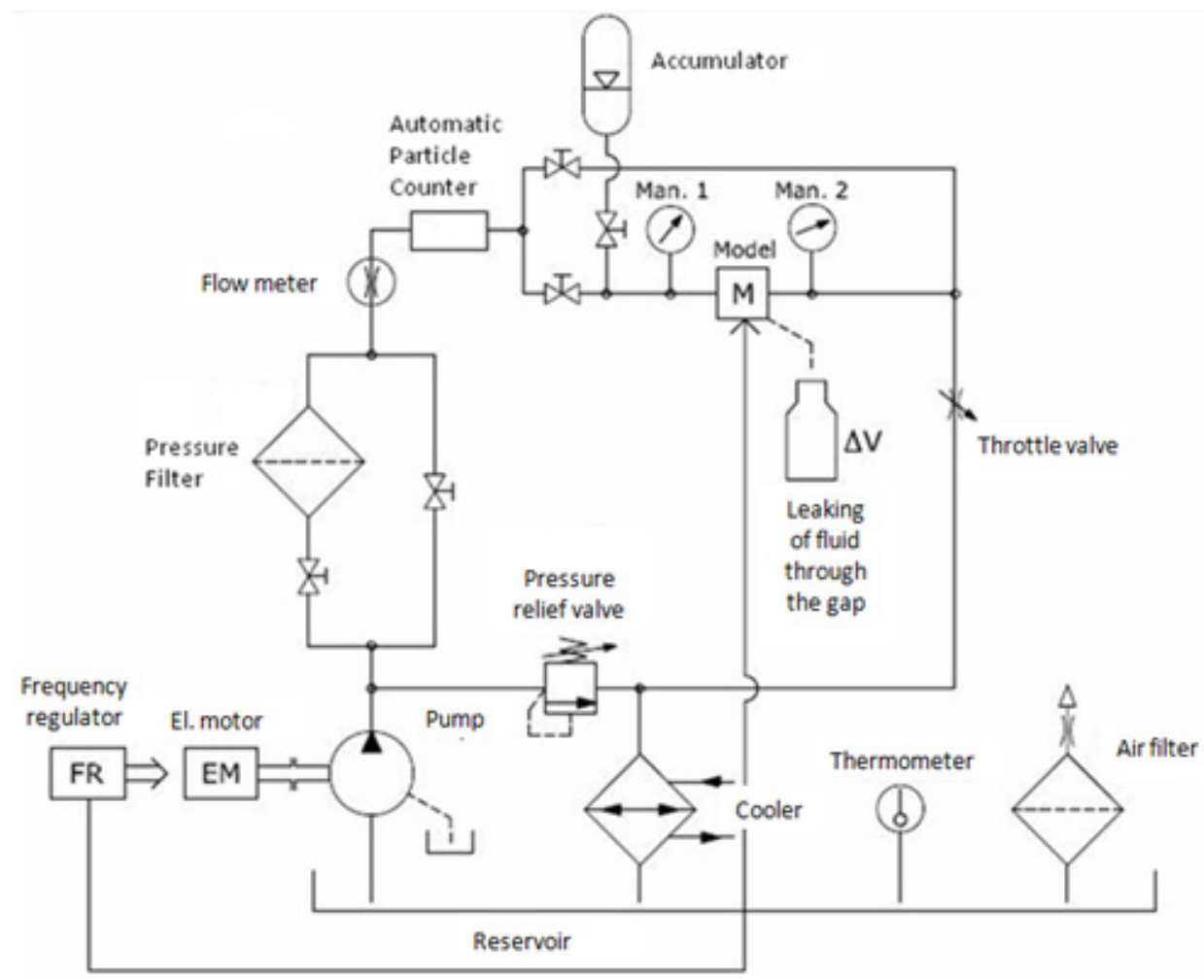

Fig. 2. Scheme of the experimental installation 
machine. Fig. 3 shows a cross-section of the directional control valve with indicated piston contact rings and cylinders within the valve body, which form the radial clearances observed in the experiment. The measurement results of piston contact ring diameters and cylinders within the valve body show that the original clearance values in the tested directional control valves are within tolerances for standard directional control valves. Table 1 shows the measured original radial clearance values for all three tested valves used in the experiment.

The following formula determines clearance values:

$$
Z_{i}=\frac{D_{i}-d_{i}}{2}
$$

where $Z_{i}$ stands for clearance value, $D_{i}$ the value of cylinder diameter in the valve body and $d_{i}$ the value of piston ring diameter.

Table 1. Starting values of the radial clearance between the piston and the valve body

\begin{tabular}{lcccc}
\hline Valve & $Z_{1}[\mu \mathrm{m}]$ & $Z_{2}[\mu \mathrm{m}]$ & $Z_{2}[\mu \mathrm{m}]$ & $Z_{2}[\mu \mathrm{m}]$ \\
\hline RV1 & 8.30 & 5.95 & 5.05 & 5.90 \\
\hline RV2 & 6.15 & 4.95 & 5.40 & 5.45 \\
\hline RV3 & 6.05 & 6.45 & 5.90 & 5.30 \\
\hline
\end{tabular}

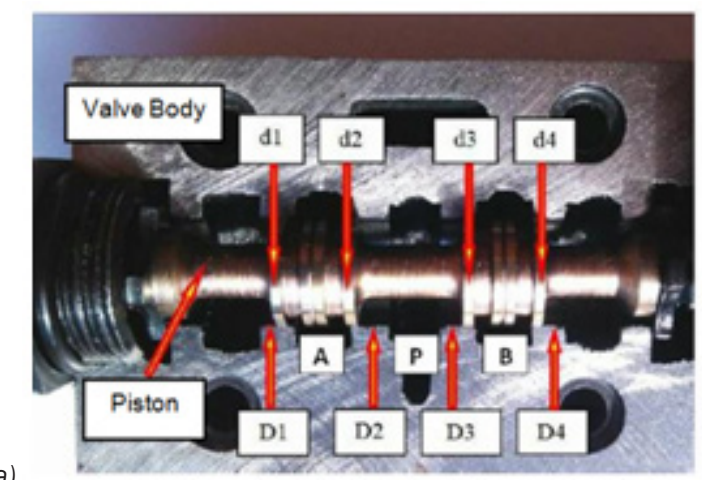

a)

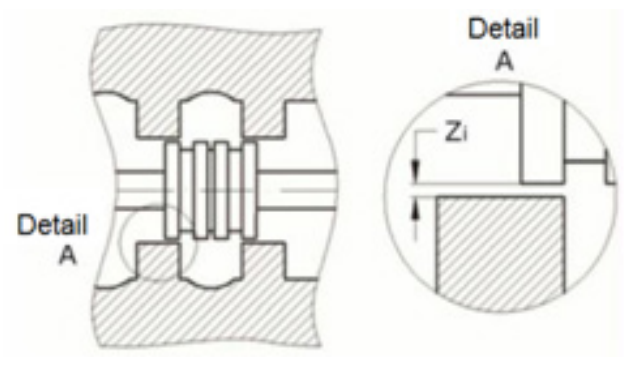

Fig. 3. A cross-sectional view of the tested directional control valve; a) Integral valve elements and diameters of the rings being monitored, and b) The surfaces in relation to which the radial gap is obtained by measuring
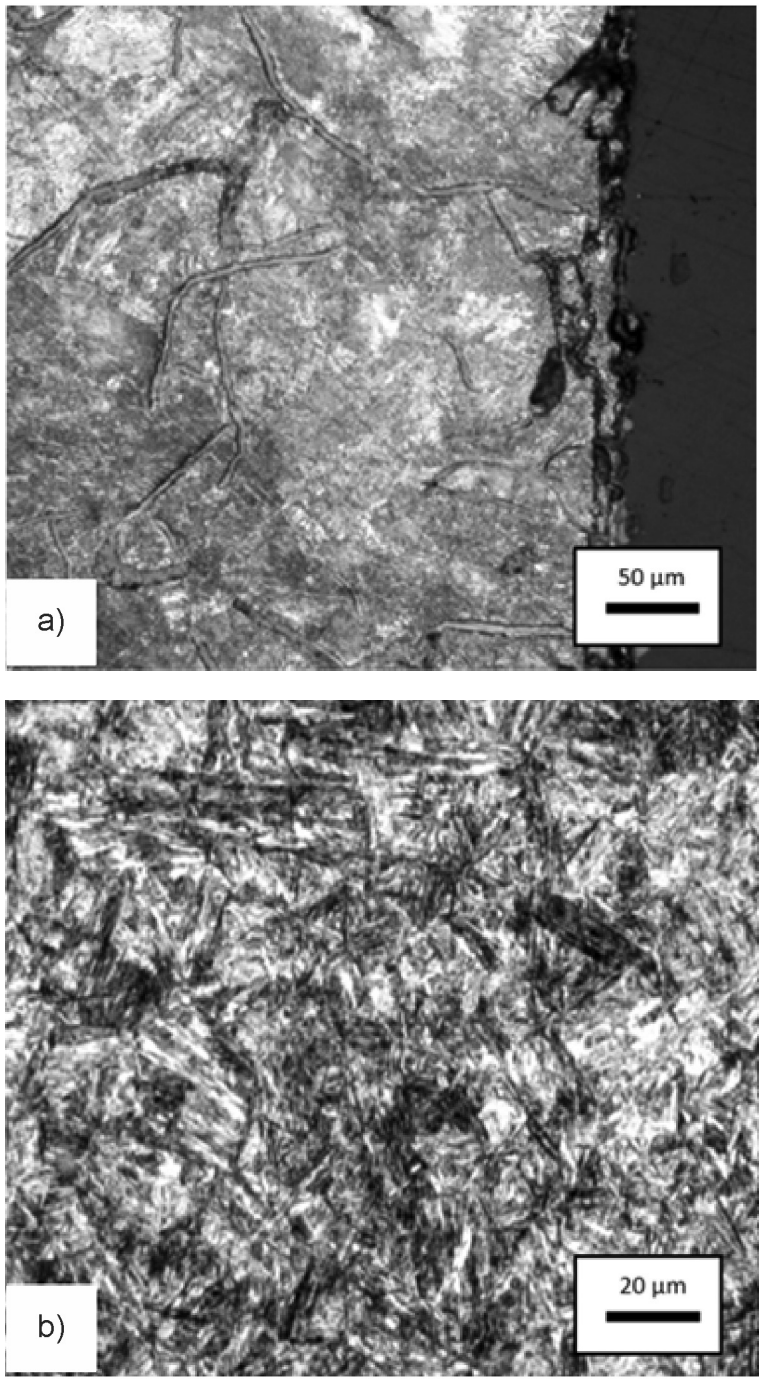

Fig. 4. The microstructure of the contact surface in the valve body and piston: a) pearlite microstructure (at 200x magnification) near the contact surface in the valve body; b) martensite microstructure (at $500 \times$ magnification) of the piston

The valve bodies are made of grey cast iron with pearlite matrix (Fig. 4a). The contact surface hardness, measured with Wolpert DIA Testor Z Brinell, is in the range of $240 \mathrm{BHN}$ to $248 \mathrm{BHN}$. The piston, made of martensitic stainless steel (Fig. 4b) is surfacehardened to approximately $0.3 \mathrm{~mm}$ depth, with the average surface hardness $927 \mathrm{HV}$.

The directional control valve, used in the experimental installation, has two working positions:

1. Neutral position (with closed flow paths);

2. Working position (fluid flow through the valve is enabled, from connection $\mathrm{P}$ towards connection A). 


\subsection{Measuring Instrumentation for Oil Cleanliness}

For experimental purposes, mineral hydraulic oil HM 46 was used. Each valve has its specified oil cleanliness level (Table 2).

Table 2. Hydraulic oil cleanliness level for the experiment

\begin{tabular}{lc}
\hline Valve & $\begin{array}{r}\text { Cleanliness level of oil for particles } \geq 4 \mu \mathrm{m}_{(\mathrm{c})} \\
\text { according to ISO } 4406: 2017[13]\end{array}$ \\
\hline RV1 & 22 \\
\hline RV2 & 21 \\
\hline RV3 & 20 \\
\hline
\end{tabular}

The oil contamination level during the operation was monitored with HIAC PM 4000 and maintained on the preset level. When particle concentration increases in relation to the preset level, the fluid filtrate through an installed pressure filter (HYDAC Betamicron) of absolute filtration fineness, with beta ratio $\beta_{5}=200$.

\subsection{Measuring Instrumentation for Pressure and Temperature Monitoring}

The pressure and temperature monitoring were performed with hand-held datalogger Hydrotechnik Multi-Handy 3010, pressure sensor - measuring range from 0 bar to 400 bar $( \pm 0.5 \%$ of final value) and temperature sensor - measuring range from $-50{ }^{\circ} \mathrm{C}$ to $200{ }^{\circ} \mathrm{C}$ (with the error limit $< \pm 0.1 \%$ of final value).

\subsection{Instrumentation for Spool Surface Scanning}

In addition to the above-mentioned measurements, contact surfaces of piston rings were examined by using a JEOL JSM 6460LV microscope.

\subsection{Experiment Working Parameters' Setup Values}

The experiment was conceived as the testing of three new directional control valves produced by the same manufacturer and of the same operating characteristics. During the experiment, installation worked with pressure $p=150$ bar, flow $Q=9.5$ 1/min and temperature $T=45^{\circ} \mathrm{C}$. All three valves were monitored up to $n=10^{6}$ working cycles.

During the operation of the system, the parameters such as pressure, flow, temperature and hydraulic oil cleanliness were monitored and maintained. The gap size between contact surfaces of piston rings and cylinders in the valve body was also monitored, as well as the changes of the fluid leakage through the clearance, weight change of the piston and the valve body due to wear, and changes of pressure drop values during the fluid flow through the open valve.

\section{RESULTS AND DISCUSSION}

Indicators that show the wear intensity of the valve contact pairs are the radial clearances values and the values of the fluid flow volume through the clearances. Tables 3 to 5 show the measured values of radial clearances between the contact surfaces of the

Table 3. Values of the radial clearance between the piston and the cylinder in the valve body RV1 (used oil cleanliness level ISO 22 [13] for particles $\left.\geq 4 \mu m_{(c)}\right)$

\begin{tabular}{|c|c|c|c|c|c|c|c|c|c|c|c|c|c|}
\hline \multirow{2}{*}{ Valve } & \multirow{2}{*}{$\begin{array}{l}\text { Radial clear. } \\
\qquad[\mu \mathrm{m}]\end{array}$} & \multicolumn{12}{|c|}{ Number of working cycles } \\
\hline & & 0 & 105 & $2 \cdot 10^{5}$ & $3 \cdot 10^{5}$ & $4 \cdot 10^{5}$ & $5 \cdot 105$ & $6 \cdot 105$ & $7 \cdot 10^{5}$ & $8 \cdot 105$ & $9 \cdot 105$ & 106 & $K_{(Z i)}$ \\
\hline \multirow{4}{*}{ RV1 } & $Z_{1}$ & 8.30 & 8.50 & 10.40 & 10.80 & 11.90 & 13.90 & 16.15 & 17.55 & 18.50 & 19.95 & 22.35 & 2.69 \\
\hline & $Z_{2}$ & 5.95 & 6.10 & 7.50 & 8.20 & 9.80 & 14.00 & 19.15 & 19.70 & 25.80 & 31.05 & 32.50 & 5.46 \\
\hline & $Z_{3}$ & 5.05 & 5.10 & 5.10 & 5.50 & 6.10 & 6.50 & 6.70 & 6.75 & 6.85 & 7.45 & 7.60 & 1.51 \\
\hline & $Z_{4}$ & 5.90 & 6.05 & 6.55 & 6.85 & 6.90 & 7.00 & 7.05 & 7.30 & 7.55 & 7.70 & 7.70 & 1.31 \\
\hline
\end{tabular}

Table 4. Values of the radial clearance between the piston and the cylinder in the valve body RV2 (used oil cleanliness level ISO 21 [13] for particles $\left.\geq 4 \mu m_{(c)}\right)$

\begin{tabular}{|c|c|c|c|c|c|c|c|c|c|c|c|c|c|}
\hline \multirow{2}{*}{ Valve } & \multirow{2}{*}{$\begin{array}{l}\text { Radial clear. } \\
\qquad \mu \mathrm{m}]\end{array}$} & \multicolumn{12}{|c|}{ Number of working cycles } \\
\hline & & 0 & 105 & $2 \cdot 105$ & $3 \cdot 105$ & $4 \cdot 10^{5}$ & $5 \cdot 10^{5}$ & $6 \cdot 105$ & $7 \cdot 10^{5}$ & $8 \cdot 105$ & $9 \cdot 105$ & 106 & $K_{(Z i)}$ \\
\hline \multirow{4}{*}{ RV2 } & $Z_{1}$ & 6.15 & 6.70 & 7.25 & 7.75 & 7.95 & 8.40 & 10.45 & 10.90 & 11.40 & 12.05 & 12.05 & 1.96 \\
\hline & $Z_{2}$ & 4.95 & 5.20 & 5.25 & 5.70 & 7.45 & 7.85 & 9.15 & 9.30 & 10.00 & 10.15 & 11.00 & 2.22 \\
\hline & $Z_{3}$ & 5.40 & 5.50 & 5.85 & 6.05 & 6.05 & 6.35 & 6.55 & 6.80 & 7.15 & 7.30 & 7.45 & 1.38 \\
\hline & $Z_{4}$ & 5.45 & 5.45 & 5.65 & 6.05 & 6.15 & 6.25 & 6.40 & 6.45 & 6.50 & 6.65 & 6.85 & 1.25 \\
\hline
\end{tabular}


Table 5. Values of the radial clearance between the piston and the cylinder in the valve body RV3 (used oil cleanliness level ISO 20 [13] for particles $\left.\geq 4 \mu m_{(c)}\right)$

\begin{tabular}{|c|c|c|c|c|c|c|c|c|c|c|c|c|c|}
\hline \multirow{2}{*}{ Valve } & \multirow{2}{*}{$\begin{array}{l}\text { Radial clear. } \\
{[\mu \mathrm{m}]}\end{array}$} & \multicolumn{12}{|c|}{ Number of working cycles } \\
\hline & & 0 & $10^{5}$ & $2 \cdot 10^{5}$ & $3 \cdot 10^{5}$ & $4 \cdot 10^{5}$ & $5 \cdot 10^{5}$ & $6 \cdot 10^{5}$ & $7 \cdot 10^{5}$ & $8 \cdot 10^{5}$ & $9 \cdot 10^{5}$ & $10^{6}$ & $K_{(Z i)}$ \\
\hline \multirow{4}{*}{ RV3 } & $Z_{1}$ & 6.05 & 6.10 & 6.15 & 6.40 & 6.60 & 6.80 & 6.90 & 7.00 & 7.25 & 7.30 & 7.70 & 1.27 \\
\hline & $Z_{2}$ & 6.40 & 6.45 & 7.75 & 8.75 & 8.85 & 8.90 & 9.10 & 9.20 & 9.50 & 10.55 & 11.00 & 1.72 \\
\hline & $Z_{3}$ & 5.75 & 5.90 & 6.10 & 6.15 & 6.30 & 6.60 & 6.75 & 6.90 & 6.95 & 7.30 & 7.55 & 1.31 \\
\hline & $Z_{4}$ & 5.30 & 5.55 & 5.60 & 5.65 & 5.95 & 6.05 & 6.05 & 6.15 & 6.20 & 6.35 & 6.50 & 1.23 \\
\hline
\end{tabular}

piston and body of the valve. The intensity of wear is interpreted with the value of the coefficient $K_{(Z i)}$, which is determined as follows:

$$
K_{(Z i)}=\frac{x_{10^{6}}}{x_{0}}
$$

$x_{10}{ }^{6}$ stands for the value of radial clearance after $10^{6}$ working cycles; $x_{0}$ the start value of the radial clearance, $Z i$ the radial clearance being monitored for the specific valve.

Based on the coefficient $K_{(Z i)}$ from Tables 3 to 5, it can be noticed that the wear intensity is drastically decreased with the increase of oil cleanliness. The largest values of the coefficient $K_{(Z i)}$ were obtained for the radial clearance $Z_{2}$ with all three tested valves. Regarding that at the time of switching of the valve into operating position, the piston ring, and cylinder, which form the clearance $Z_{2}$, were at the front of the fluid stream impact. Intensive wearing in this section was expected, but the intensity of the clearance change could not be anticipated.

Turbulent movement of the fluid carrying solid particles produces an aggressive impact on the edges of the piston ring, and on the rim surfaces that provide non-contact sealing. The longitudinal scratches over the piston rings' contact surfaces, which are in Fig. 5 , indicate the presence of high abrasive wear. At the front side of the piston, in Fig. $5 \mathrm{c}$, some parts of the frontal surface have been broken off, which points to another wear mechanism, i.e. erosion combined with fatigue.

The wear process, as a process that by definition represents a progressive removing of material from the contact surfaces which are mutually sliding one against another [14], in this case gradually causes an increase in the size of radial clearance, resulting in the increase of volume losses. The volume loss results from the decrease of the actuators' operating speed. In the valve, the losses cause pressure drop increase during the fluid flow through the valve, as well as the fluid temperature increase, which causes viscosity to decrease. The occurrences above decrease the energy efficiency as well as the dynamic performance of the entire system [15] and [16].

To graphically present the wear intensity in the performed experiments and define it as a specific mathematical model, the Least Square fitting method and MATLAB software were used. The result of the analysis showed that the second order polynomial function was the most representative for the interpretation of the experimental, numerical data because it had the highest values of determination coefficient and the minimal sum of the squares of residuals. In addition to the polynomial function, other mathematical models were analyzed, with the results shown in Table 6.
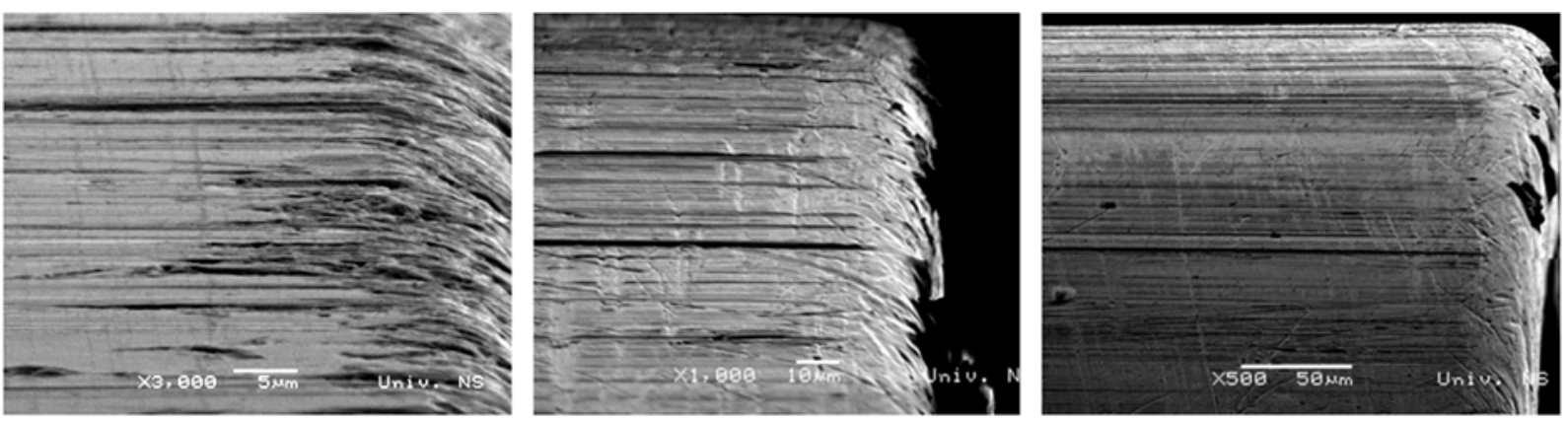

Fig. 5. SEM images of the damaged piston edge that forms the radial clearance Z2 under various magnitudes 
Table 6. Determination coefficient values for different functions derived from collected radial clearance data

\begin{tabular}{|c|c|c|c|}
\hline \multirow[b]{2}{*}{ Function } & Valve RV1 & Valve RV2 & Valve RV3 \\
\hline & \multicolumn{3}{|c|}{$\begin{array}{c}\text { Determination coefficient / } \\
\text { Sum of the squares of residuals }\end{array}$} \\
\hline Linear & 0.9376 / 61.92 & $0.9628 / 1.880$ & $0.9067 / 1.962$ \\
\hline $\begin{array}{l}\text { Second order } \\
\text { polynomial }\end{array}$ & $0.9838 / 16.05$ & $0.9629 / 1.876$ & $0.9154 / 1.780$ \\
\hline Exponential & $0.9753 / 24.50$ & $0.9458 / 2.744$ & $0.8924 / 2.263$ \\
\hline
\end{tabular}

The mathematical model of radial clearance change $(s)$ for the RV1 valve, which was operating with ISO 22 oil cleanliness level for particles $\geq 4$ $\mu \mathrm{m}_{(\mathrm{c})}$.

$$
s_{R V 1}=2.312 \cdot 10^{-11} \cdot n^{2}+5.949 \cdot 10^{-6} \cdot n+5.273 .
$$

The $n$ stands for a number of working cycles. The mathematical model of radial clearance change $(s)$ for the RV2 valve, which was operating with ISO 21 oil cleanliness level for particles $\geq 4 \mu \mathrm{m}_{(\mathrm{c})}$.

$$
s_{R V 2}=-2.098 \cdot 10^{-13} \cdot n^{2}+6.864 \cdot 10^{-6} \cdot n+4.459 \text {. }
$$

The mathematical model of radial clearance change $(s)$ for the RV3 valve, which was operating with ISO 20 oil cleanliness level for particles $\geq 4$ $\mu \mathrm{m}_{(\mathrm{c})}$.

$$
s_{R V 3}=-1.457 \cdot 10^{-12} \cdot n^{2}+5.621 \cdot 10^{-6} \cdot n+6.468 .
$$

A similar study was conducted by Liu et al. [17], in order to define the valve service life model.

Theoretical capacity in Table 7 has been determined by the calculation formula for flow through the annular clearance [18]:

$$
\Delta Q_{t}=\frac{\pi \cdot d \cdot \Delta p \cdot s^{3}}{12 \cdot \eta \cdot L}
$$

where $d$ stands for piston diameter, $\Delta p$ pressure drop, $s$ clearance, $\eta$ dynamic viscosity and $L$ clearance length.

In addition to the clearance size, solid particles contained in the working fluid cause a considerable impact on the size of volume losses. Their impact is opposite to the impact of the clearance size, i.e. if the increase in the clearance size causes the increase in volume losses, the increase in the number of solid particles causes the decrease in volume losses. It occurs because solid particles aggregate at the clearance location, forming in this way deposits that temporarily decrease or obstruct the fluid flow through the clearance. The probability of formation of solid particle deposits is higher in case of static conditions of operation when the piston within the valve does not move [19] to [21].
Table 7 shows the values of annular leakage $\left(\Delta Q_{e}\right)$, measured after each $10^{5}$ working cycles under static conditions of valve operation (which means that there is no spool position change in axial direction), for all three valves. It should be noted that under static conditions of operation the directional control valve is in the neutral position (Fig. 6). Leakage flow is determined as a captured volume $(\Delta V[1])$ per time unit $(t[\mathrm{~min}])$.

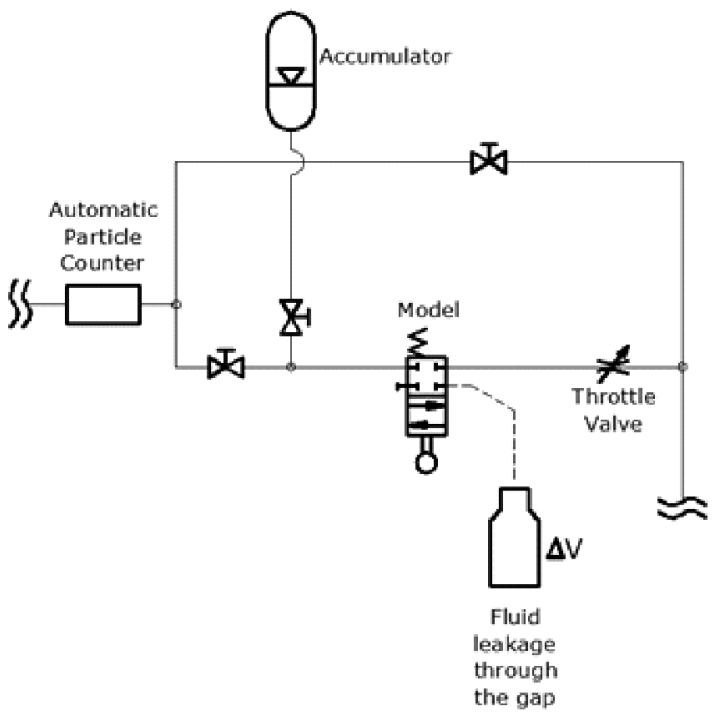

Fig. 6. Valve position during the measurement of the annular leakage

Table 8 shows the results of the experimental data set analysis by the least square fitting method. According to the results, the following mathematical models of annular fluid leakage are derived. For the RV1 valve, which was operating with ISO 22, the oil cleanliness level for particles $\geq 4 \mu \mathrm{m}_{(\mathrm{c})}$.

$$
\Delta Q_{R V 1}=-2.063 \cdot 10^{-12} \cdot n^{2}+8.054 \cdot 10^{-6} \cdot n+7.65 .
$$

The $n$ stands for a number of working cycles. The mathematical model of annular fluid leakage $(\Delta Q)$ for the RV2 valve, which was operating with ISO 21 oil cleanliness level for particles $\geq 4 \mu \mathrm{m}_{(\mathrm{c})}$.

$$
\Delta Q_{R V 2}=4.615 \cdot 10^{-13} \cdot n^{2}+4.018 \cdot 10^{-6} \cdot n+6.942 .
$$

The mathematical model of annular fluid leakage $(\Delta Q)$ for the RV3 valve, which was operating with ISO 20 oil cleanliness level for particles $\geq 4 \mu \mathrm{m}_{\text {(c) }}$.

$$
\Delta Q_{R V 3}=7.271 \cdot e^{\left(5.003 \cdot 10^{-7} \cdot n\right)} .
$$

Additionally, it should be noted that the formed deposits of solid particles are exposed to a constant impact of pressure that, under certain conditions, 
Table 7. A comparative overview of theoretically calculated $\left(\Delta Q_{t}\right)$ and experimentally measured $\left(\Delta Q_{e}\right)$ flow values through the annular clearance $\mathrm{Z} 3$ in static operating conditions

\begin{tabular}{|c|c|c|c|c|c|c|c|c|c|}
\hline \multirow{2}{*}{$\begin{array}{c}\text { Number of } \\
\text { working } \\
\text { cycles }\end{array}$} & \multicolumn{3}{|c|}{ RV1 (ISO 22 for $4 \mu \mathrm{m}_{(\mathrm{c})}$ ) } & \multicolumn{3}{|c|}{ RV2 (ISO 21 for $4 \mu \mathrm{m}_{(\mathrm{c})}$ ) } & \multicolumn{3}{|c|}{ RV3 (ISO 20 for $4 \mu \mathrm{m}_{(\mathrm{c})}$ ) } \\
\hline & $\Delta Q_{t}[\mathrm{ml} / \mathrm{min}]$ & $\Delta Q_{e}[\mathrm{ml} / \mathrm{min}]$ & $\Delta_{R V 1}{ }^{*}$ & $\Delta Q_{t}[\mathrm{ml} / \mathrm{min}]$ & $\Delta Q_{e}[\mathrm{ml} / \mathrm{min}]$ & $\Delta_{R V 2}{ }^{*}$ & $\Delta Q_{t}[\mathrm{ml} / \mathrm{min}]$ & $\Delta Q_{e}[\mathrm{ml} / \mathrm{min}]$ & $\Delta_{R V 3}{ }^{*}$ \\
\hline 0 & 10.08 & 7.10 & 2.98 & 12.33 & 6.40 & 5.93 & 14.88 & 6.80 & 8.08 \\
\hline 105 & 10.38 & 8.40 & 1.98 & 13.02 & 7.70 & 5.32 & 16.08 & 8.00 & 8.08 \\
\hline $2 \times 10^{5}$ & 10.38 & 9.70 & 0.68 & 15.67 & 8.10 & 7.57 & 17.77 & 8.40 & 9.37 \\
\hline $3 \times 10^{5}$ & 13.02 & 10.50 & 2.52 & 17.34 & 8.60 & 8.74 & 18.21 & 8.40 & 9.81 \\
\hline $4 \times 10^{5}$ & 17.77 & 11.00 & 6.77 & 17.34 & 8.50 & 8.84 & 19.57 & 8.80 & 10.77 \\
\hline $5 \times 10^{5}$ & 21.50 & 10.80 & 10.70 & 20.04 & 8.70 & 11.34 & 22.51 & 9.20 & 13.31 \\
\hline $6 \times 10^{5}$ & 23.54 & 11.10 & 12.44 & 22.00 & 9.40 & 12.60 & 24.08 & 10.00 & 14.08 \\
\hline $7 \times 10^{5}$ & 24.08 & 11.90 & 12.18 & 24.61 & 9.94 & 14.67 & 25.72 & 10.30 & 15.42 \\
\hline $8 \times 10^{5}$ & 25.16 & 12.80 & 12.36 & 28.61 & 10.50 & 18.11 & 26.28 & 10.60 & 15.68 \\
\hline $9 \times 10^{5}$ & 32.37 & 13.20 & 19.17 & 30.45 & 10.70 & 19.75 & 30.45 & 11.30 & 19.15 \\
\hline 106 & 34.36 & 14.00 & 20.36 & 32.37 & 11.70 & 20.67 & 33.69 & 12.20 & 21.49 \\
\hline
\end{tabular}

can break through the barrier, which causes a sudden increase in the fluid flow through the clearance together with the particles [19].

Table 8. Determination coefficient values for different functions derived from collected annular fluid leakage data

\begin{tabular}{|c|c|c|c|}
\hline \multirow[b]{2}{*}{ Function } & Valve RV1 & Valve RV2 & Valve RV3 \\
\hline & \multicolumn{3}{|c|}{$\begin{array}{c}\text { Determination coefficient / } \\
\text { Sum of the squares of residuals }\end{array}$} \\
\hline Linear & $0.9439 / 2.347$ & $0.9560 / 1.016$ & $0.9700 / 0.754$ \\
\hline $\begin{array}{l}\text { Second order } \\
\text { polynomial }\end{array}$ & $0.9526 / 1.982$ & $0.9568 / 0.998$ & $0.9733 / 0.671$ \\
\hline Exponential & $0.9263 / 3.084$ & $0.9561 / 1.014$ & $0.9738 / 0.660$ \\
\hline
\end{tabular}

Table 9. A comparative display of the mass loss for all three valves

\begin{tabular}{lcc}
\hline \multirow{2}{*}{ Valve } & \multicolumn{2}{c}{ Percentage of mass loss } \\
\cline { 2 - 3 } & Valve body [\%] & Piston [\%] \\
\hline RV1 & 0.0350 & 0.0031 \\
\hline RV2 & 0.0066 & 0.0014 \\
\hline RV3 & 0.0055 & 0.0015 \\
\hline
\end{tabular}

Weighing of the valve body and piston mass confirms that both of the components had losses in the mass (Table 9), where the valve body lost more mass in regards to the piston, which fulfils the expectation, taking into account the hardness of the contact surfaces of the valve body and piston.

As the mass loss is very small, this impact on the performances of the directional control valve can be neglected. Nevertheless, it shows how much the valve is worn in terms of mass. However, it should be noted that the removed material from the contact surfaces of working elements produces new particles that are distributed within the fluid through the system and influence other system components' performance with the non-contact sealing mechanism. These particles have significant influence were abrasive, and erosive wear is present.

In order to observe the intensity of disturbances during the oil flow through the open valve due to oil contamination, the pressure drop was measured. In this case, the valve is in working position in order to enable full fluid flow from port $\mathrm{P}$ towards port $\mathrm{A}$. The comparative pressure drop diagram in Fig. 6 shows that in all three cases, the pressure drop has a tendency to increase, which decreases with a higher cleanliness level of the working fluid.

By decreasing solid particles' concentration in the working fluid (observed from experiment No. 1 towards experiment No. 3), the intensity of the pressure drop change decreases during the exploitation of the directional control valve. An interesting observation, based on the diagrams from Fig. 7, is a deviation of measured pressure drop values. Diagrams in Fig. 8 interpret experimental results by the normal distribution function, with the purposed of expressing more clearly the differences in terms of deviation of the results around the mean value. Table 10 shows the values of standard deviations for all three valves. These deviations partly represent the result of the pressure sensor measuring uncertainty, but it also is shown that the cleanliness level of working fluid produces an impact on the pressure drop value.

Due to the occurrence of pressure drop, as well as volume losses, the efficiency of hydraulic systems decreases. Less efficient hydraulic systems will have lower competitiveness compared to other drive systems. For this reason, with sophisticated hydraulic 
systems, one should pay considerable attention regarding the conditioning of working fluid, which has multiple important effects.

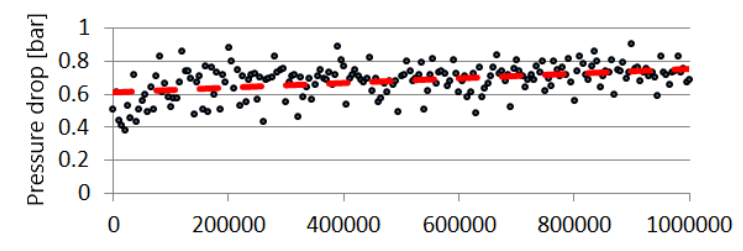

a)

Number of working cycles
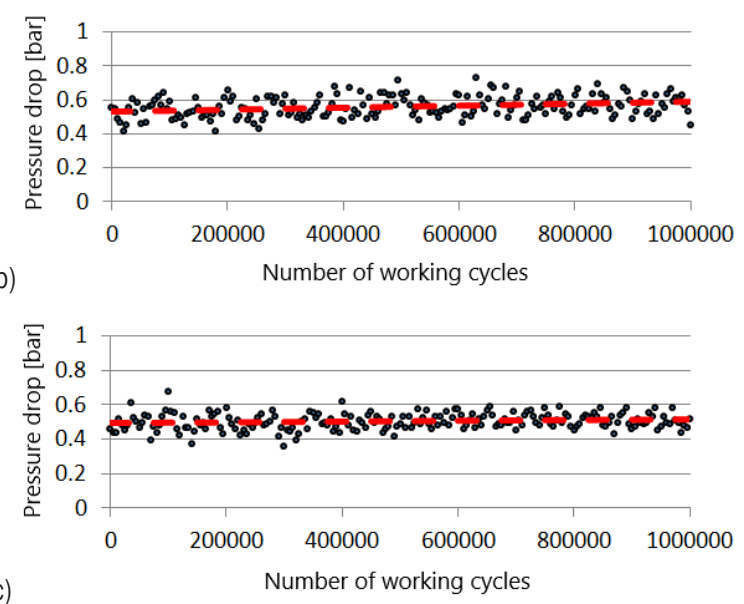

Fig. 7. Pressure drop diagrams for all three valves: a) for $R V 1$; b) for $R V 2$; c) for $R V 3$, and flow rate $Q=9.5 \mathrm{l} / \mathrm{min}$

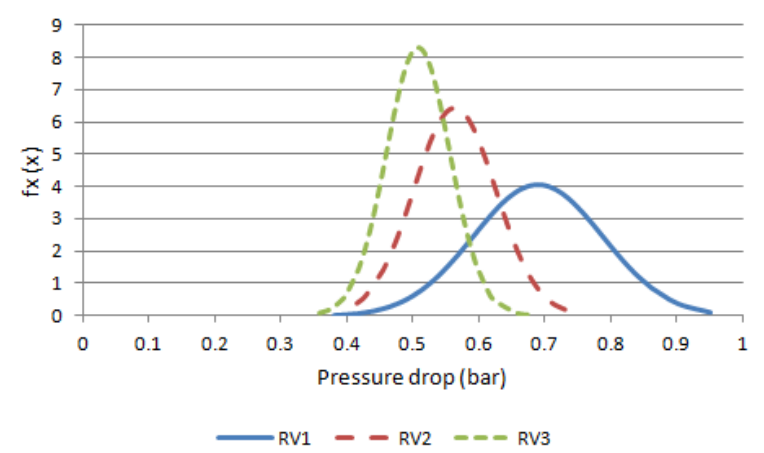

Fig. 8. Comparison of normal distribution diagrams for pressure drop values

Table 10. Pressure drop deviation values for all three valves

\begin{tabular}{cccc}
\hline & RV1 & RV2 & RV3 \\
\cline { 2 - 4 } & $\begin{array}{c}\text { ISO 22 } \\
\text { for } 4 \mu \mathrm{m}_{(\mathrm{c})}\end{array}$ & $\begin{array}{c}\text { ISO } 21 \\
\text { for } 4 \mu \mathrm{m}_{(\mathrm{c})}\end{array}$ & $\begin{array}{c}\text { ISO } 20 \\
\text { for } 4 \mu \mathrm{m}_{(\mathrm{c})}\end{array}$ \\
\hline$\sigma=\sqrt{\frac{1}{n} \sum_{i=1}^{n}\left(x_{i}-\bar{x}\right)^{2}}$ & 0.09811 & 0.06187 & 0.04790 \\
\hline
\end{tabular}

\section{CONCLUSIONS}

Based on the experimental results and performed analyses, in this study, it has been confirmed that solid particles produce an impact on working performances of the hydraulic control valve. The particles which come into a clearance intensify the wear process on contact surfaces and the change in their topology, generating new particles, and under certain conditions, they may form deposits resulting in mechanical and flow blockage. Such consequences are particularly present in the components with precise control and regulation elements with non-contact sealing, which are especially sensitive to solid particles' impact due to small clearances.

The obtained experimental results show differences in the wear intensity that were expected. In the case of increased cleanliness level from ISO 22 (for particles $\geq 4 \mu \mathrm{m}_{(\mathrm{c})}$ ) to ISO 21 (for particles $\geq 4$ $\left.\mu \mathrm{m}_{(\mathrm{c})}\right)$, the achieved decrease of the wear intensity was $K_{Z 2(R V 1)} / K_{Z 2(R V 2)}=2.5$ times, and with the decrease from ISO 22 (for particles $\geq 4 \mu \mathrm{m}_{(\mathrm{c})}$ ) to ISO 20 (for particles $\left.\geq 4 \mu \mathrm{m}_{(\mathrm{c})}\right)$, the decrease of the wear intensity was $K_{Z 2(R V 1)} / K_{Z 2(R V 3)}=3$ times.

In terms of volume losses, if the last measured value and the first measured value of the flow through a clearance are taken into account, the results show that in the case of using oil cleanliness level ISO 22 (for particles $\geq 4 \mu \mathrm{m}_{(\mathrm{c})}$ ), the ratio is equal to $\Delta Q_{e\left(10^{6}\right)} / \Delta Q_{e(0)}=1.97$, and in case of using oil cleanliness level ISO 21 (for particles $\geq 4 \mu \mathrm{m}_{(\mathfrak{c})}$ ) the ratio is equal to $\Delta Q_{e\left(10^{6}\right)} / \Delta Q_{e(0)}=1.83$, and in case of using oil cleanliness level ISO 20 (for particles $\geq 4$ $\left.\mu \mathrm{m}_{(\mathrm{c})}\right)$ the ratio is $\Delta Q_{e\left(10^{6}\right)} / \Delta Q_{e(0)}=1.79$.

Additionally, it is evident that between theoretically calculated and experimentally measured values of the flow through the clearance, there are differences which increase with the increase of the value of clearance, but the experimental values have much lower growth in comparison to theoretically calculated values of the flow.

By measuring pressure drop values during the experiment, it was found that the oil cleanliness level has an impact on the pressure drop increase. Due to the pressure drop increase, more heat is generated which decreases overall system efficiency.

\section{REFERENCES}

[1] Parker Hannifin Ltd. (2010). Hydraulic fluids: Controlling contamination in hydraulic fluids. Filtration \& Separation, vol. 47, no. 3, p. 28-30, Dol:10.1016/s0015-1882(10)70127-0. 
[2] Hydac International (2012). Filtration Handbook. from http:// www.hydac.com.tr/download.html?path=templates\%2Fhydac \%2Fupload\%2Ffile\%2Fproducts\%5CFiltrasyon\%5Fbrosur1\%2 Epdf, accessed on 23-11-2017.

[3] Ng, F., Harding, J.A., Glass, J. (2017). Improving hydraulic excavator performance through in line hydraulic oil contamination monitoring. Mechanical Systems and Signal Processing, vol. 83, p. 176-193, D0l:10.1016/j. ymssp.2016.06.006.

[4] Kovari, A. (2009). Influence of cylinder leakage on dynamic behavior of electrohydraulic servo system. $7^{\text {th }}$ International Symposium on Intelligent Systems and Informatics, p. 375379, D0I:10.1109/SISY.2009.5291129.

[5] Strmčnik, E., Majdič, F. (2017). Comparison of leakage level in water and oil hydraulics. Advances in Mechanical Engineering, vol. 9, no, 11, p. 1-12, Dol:10.1177/1687814017737723.

[6] Battat, B., Babcock, W. (2003). Understanding and reducing the effects of contamination on hydraulic fluids and systems. The Advanced Materials \& Processes Technology Information Analysis Center Quarterly, vol. 7, no. 1, p. 11-15.

[7] Nash, T. (2006). Filtration: It's the little things that get you, Hydraulics and Pneumatics, no. 5, p. 29-31.

[8] Bosch Rexroth AG (2011). Rexroth Oil Cleanliness Booklet, from http://www.hksm.com.tr/Images/dosya/rexroth-oilclean.pdf, accessed on 28-08-2018.

[9] Kumar, M., Mukherjee, P.S., Misra, N.M. (2013). Advancement and current status of wear debris analysis for machine condition monitoring: a review. Industrial Lubrication and Tribology, vol. 65, no. 1, p. 3-11, DOl:10.1108/00368791311292756.

[10] Karanović, V., Jocanović, M., Jovanović, V. (2014). Review of development stages in the conceptual design of an electrohydrostatic actuator for robotics. Acta Polytechnica Hungarica, vol. 11, no. 5, p. 59-79, DOl:10.12700/APH.11.05.2014.05.4.

[11] Johnson, J.L. (2010). Q\&A about servo and proportional valves. Hydraulics and Pneumatics, no. 7, p. 30-39.
[12] ISO 12669:2017. Hydraulic Fluid Power - Method for Determining the Required Cleanliness Level (RCL) for a System. International standardization organization, Geneva.

[13] ISO 4406:2017. Hydraulic fluid power - Fluids - Method for coding the level of contamination by solid particles. International standardization organization, Geneva.

[14] Rabinowicz, E. (1995). Friction and Wear of Materials. John Wiley and Sons, New York.

[15] An, L., Sepehri, N. (2005). Hydraulic actuator leakage fault detection using extended Kalman filter. International Journal of Fluid Power, vol. 6, no, 1, p. 41-51, D0l:10.1080/1439977 6.2005.10781210.

[16] Kovari, A. (2015). Effect of leakage in electrohydraulic servo systems based on complex nonlinear mathematical model and experimental results. Acta Polytechnica Hungarica, vol. 12, no. 3, p. 129-146, DOl:10.12700/APH.12.3.2015.3.8.

[17] Liu, Y., Ma, B., Zheng, C., Zhang, S. (2015). Degradation modeling and experiment of electro-hydraulic shift valve in contamination circumstances. Advances in Mechanical Engineering, vol. 7, no. 5, p. 1-9, DOI:10.1177/1687814015585925.

[18] Basta, T.M. (1971). Engineering Hydraulics. Mashinostroenie, Moscow.

[19] Jocanović, M. (2010). Approach to Research and Define the Model for the Calculation of Flow of Solid Particles with a Mass of Mineral Oil through the Gaps in a Function of the Constructive Operating Parameters of Hydraulic Components. Ph.D. thesis, University of Novi Sad, Novi Sad.

[20] Fitch, E.C., Hong, I.T. (2004). Hydraulic System Design for Service Assurance, BarDyne Inc, Stillwater.

[21] Casey, B. (2012). How Silt Lock Can Destroy Hydraulic Valves, from http://www.machinerylubrication.com/Read/28853/ silt-lock-hydrauli, accessed on 03.09.2018. 